M. A. Krishnaswamy, N. L. Lahiry, S. B. Kadkol, S. Venkat Rao, G. D. Revankar und K. C. Suresh Chandra: Verwendung von Fischkartoffelflocken in der mensehlichen Ernährung. (A nutritional evaluation of fish-potato flake.) (Mysore, Indien, Central Food Technol. Res. Inst.) Food Technol. 19, H. 4, 197-200 (1965).

Das indische Forschungsinstitut entwickelte protein reiche Lebensmittel, die aus einer Mischung von Fisch mit Weizen, Weizengrieß, Tapiocamehl usw. bestehen. Die Erzeugnisse werden nach entsprechender Vorbehandlung zu Flocken getrocknet, deren Proteingehalt etwa $40 \%$ beträgt. Es wurde auch eine Fischpaste in Büchsen hergestellt, die eine tafelfertige Mischung aus gekochtem Fiseh und Kartoffeln darstellt und im Haushalt vielfältig verwendet werden kann. Neuerdings gelang es, diese Fischpaste zu entwässerten Fischkartoffelflocken weiterzuentwickeln. Man hofft, daß ein solches getrocknetes Erzeugnis billiger ist als ein in Dosen verpacktes und sich besonders zur Bekämpfung der Eiweißunterernährung im indischen Raum eignet. Die Arbeit beschäftigt sich mit der Verwendung dieses aus örtlichen Arten von Süßwasserfischen hergestellten Erzeugnisses und vergleicht den Nährstoffgehalt mit dem von rohen und gekochten Fischen. Fischkartoffelflocken, aus einer Mischung von gekochten Kartoffeln und eines Süßwasserfisches (Burbas carnaticus) hergestellt, haben eine sahneähnliche Farbe, einen angenehmen, milden Fischgeschmack und eine knusprige Beschaffenheit. Der Proteingehalt beträgt etwa 45\%. Das Produkt befriedigt in hygienischer Hinsicht; es war frei von Enterokokken, Salmonellen, Streptokokken und pathogenen Anaerobiern. Trotz leichter Veränderungen in Farbe und Geruch war das Erzeugnis nach 4 Nonaten bei einer Lagerung bei $37^{\circ} \mathrm{C}$ noch genießbar.

R. Dietrich (Bremerhaven)

\title{
Sonstige Tierarten
}

G. Lusk, M. Karel und S. A. Goldblith: Die Auswirkung einiger Parameter auf den Ablauf der Gefriertrockmung von Krabben. (Effect of some processing parameters on the rates of freezedrying of shrimp.) (Cambridge, Mass., USA, Dept. of Nutr. and Food Sci., Massachusetts Inst. of Technol.) Food Technol. 19, H. 4, 188-190 (1965).

Um die Wirtschaftlichkeit der Gefriertrocknung von Lebensmitteln zu erhöhen, wurden diejenigen Faktoren überprüft, die geeignet erschienen, die Trocknungszeit zu beeinflussen. Die vorliegende Arbeit befaßt sich mit den Auswirkungen einiger veränderlicher Faktoren, und zwar mit dem Einfluß der Höhe der Trocknungstemp., der Gefriertemp. des Gutes und des Kammerunterdrucks während der Trocknung. Die Ergebnisse der Versuchsreihen sind in übersichtlichen Kurven wiedergegeben. Bei Anwendung einer Anfangstrocknungstemp. von $79,4^{\circ} \mathrm{C}$ und einer stufenweisen Reduzierung auf $51,7^{\circ} \mathrm{C}$ war es möglich, die Trocknungszeit von 10,5 auf $8,5 \mathrm{Std}$ zu erniedrigen. Bei einer Anfangstrocknungstemp. von $121,1^{\circ} \mathrm{C}$ gelang es, die Trocknungszeit weiter auf 8 Std zu verkürzen, doch können diese Zeiten unzweifelhaft noch weiter reduziert werden. Krabben, die in flüssigem Stickstoff eingefroren worden waren, erforderten eine beträchtlich längere Trocknungszeit als Proben, die bei $-17,8^{\circ} \mathrm{C}$ gefroren wurden. Dagegen wurden keine wesentlichen Unterschiede in den Trocknungsgeschwindigkeiten bei einem Kammerunterdruck von $1,5 \mathrm{~mm} \mathrm{Hg}$ und $0,08 \mathrm{~mm} \mathrm{Hg}$ festgestellt.

R. Dietrich (Bremerhaven)

\section{Milch und Milcherzeugnisse}

\section{Mitch}

H. Rüssel: Der Bleigehalt von Milch aus Norddeutschland. (Hannover, Chem. Inst. d. Tierärztl. Hochschule.) Arch. Lebensmittel-Hyg. 16, 82-83 (1965).

Es wird über ein Verfahren zur Bestimmung von Blei in Milch berichtet. Die salzsauren Lösungen der Milchaschen wurden direkt polarographiert. Mit der Kemula-Elektrode wird ein Quecksilbertropfen definierter Größe erzeugt. Bei der folgenden Elektrolyse ist dieser Tropfen die Kathode, an der das Blei als Amalgam abgeschieden wird. Bei der Wiederauflösung des Bleies entsteht ein StromstoB, der bei konstanten Bedingungen der Bleikonzentration proportional ist. Die Höhe des Stromstoßes wird mit Werten einer Fichreihe verglichen.

Mit den erhaitenen Werten wurde eine Varianzanalyse durchgeführt. Die biologische Varianz war hochsignifikant größer als der Versuchsfehler. Als Gesamtstreuung errechnete sich $s=3,5$.

Der Normalgehalt der Milch von Kühen aus der Umgebung Hannovers bewegte sich zwischen 7,6 und $21,6 \mu \mathrm{g} / \mathrm{kg}$ Blei. Milch aus der Umgebung einer Bleihütte enthielt 35- $75 \mu \mathrm{g} / \mathrm{kg}$ Blei. 